\title{
Design and Simulation of Car Windshield Broken Mechanism Based on ABAQUS
}

\section{Tao Jiang}

Mechanical \& Electrical Engineering of College Taizhou vocational and technical college, Taizhou 318000, China

\begin{abstract}
Automotive glass is one of the most important parts of automobile, the performance of automobile glass is directly related to an important indicator of the safety of passengers and fuel economy. But in the face of all kinds of natural disasters and in the traffic accident, the doors and windows can't be open, so many people died of suffocation before the arrival of rescue workers. In this paper, a kind of window crusher with pure mechanical structure is designed, then simulate and optimize the mechanical using ABAQUS, in the case of doors and windows can't be opened, the driver and passengers can escape from the car, therefore, this design can enhance the safety when using the vehicle.
\end{abstract}

KEYWORD: Mine ventilation gas; orthogonal test; operating parameter; reactor performance

\section{INTRODUCTION}

With the progress of the social and the development of the economic, the car gradually entered the common people's family as a transport. From 2006, the popularity of cars entered into the accelerated period. Starting in 2009 , the private cars entered the accelerated phase.

In order to create a comfortable, quiet ride and secure environment, we must continue to enhance the strength and sealing material of a vehicle. Andin order to enhance the grade of the vehicle, more and more devices are electrically controlled.

In recent years, as global climate change, floods caused by heavy rain flooding, when the car was flooded, vehicle power outages, the doors and windows controlled by electronic components due to can't be open, the death of the occupant is very common. Many news report of such incidents. In addition, in accidents, since the vehicle window sealed, rescue failed and then caused many Casualties because the car window can't be open.

In this paper, a kind of window crusher with pure mechanical structure is designed, then simulate and optimize the mechanical using ABAQUS, in the case of doors and windows can't be opened, the driver and passengers can escape from the car, therefore, this design can enhance the safety when using the vehicle.

\section{MECHANISM DESIGN OF WINDOW GLASS CRUSHER}

Automotive glass give passengers a full range of good sight, shelter from the storm, so it must have sufficient strength to prevent from the stone and other things out of the car. Electric windows have been prepared in the vast majority of cars, In case of accidents and other reasons, power, it will inevitably lead to passengers trapped inside. But through all kinds of investigation, many private car has no safety hammer and other tools to break the windows, in many cars, there has tool to break the windows but the limited capacity can't complete the task.

\subsection{Analysis of car window Material}

Now the species of glass used in the car is divided into two types: laminated glass and tempered glass (Yong T, 2010). The front windshield glass is mainly laminated glass, rear windshield and side door glass is tempered glass. Laminated glass is made of two or more than two pieces of glass, with a transparent adhesive bonded to a solid composite glass products (A llen T J et al, 1998). Laminated glass has a high Impact resistance and penetration resistance performance, by impact crushing, generally speaking, the external shock can't penetrate the glass, glass fragments couldn't fly from the glue layer, and thus it plays a key role in safety protection. 
Currently in the laminated glass production, the most used intermediate bonding material is PVB film, the other is SGP, EVA, EN, etc (Seshadri M et al, 2002) (Oda J et al, 1998).

Because of the advantages of the safety of the laminated glass, the application of the laminated glass has become more and more widespread in aviation, vehicle, building and other fields, especially used as a structural materials in recent years (Oda $\mathrm{J}$ et al, 1995).

\subsection{Mechanism design of broken Window machine}

In this paper the structure using purely mechanical mechanism to break the automobile glass is designed, the structure is compact, lightweight and easily to use.

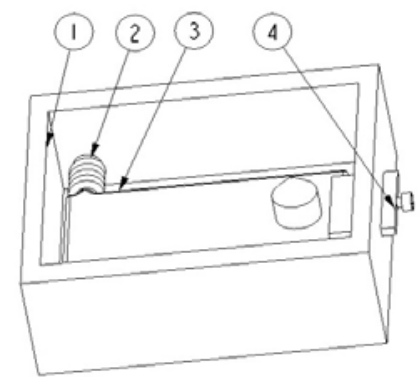

1 case; 2 compression spring; 3 breaker plate; 4 Dashboard. Fig 1. The Schematic of broken window mechanism

As shown in Figure 1, the crusher for vehicle is designed to box type mechanism. Part1 is shell, wrapped to the crusher, also provided with bearing holes for fixing the broken plate, Part 2 is a compression spring, the compression spring rebound driven crushing plate impact glass, Part 3 is crushing plate, plate is fixed with a drill, for the crash of glass, part 4 is control panel, the board is used to limit the crushing plate, when the driver in car wants to break the window he can pull the plate, The board is released to smashed the glass.

\section{STRUCTURE SIMULATION AND OPTIMIZATION}

\subsection{Research status of Impact damage resistance of windshield}

Nathan and Behr (Nathan D.K et al, 2010) did an experiment conduct using the impact of ball, discussed the impact of failure phenomena in the course of the underlying glass. Zhao (Zhao $\mathrm{S}$ et al, 2012) put forward the theory of the dynamic response of laminated glass plate based on the theory of large perturbation, in order to analyze the impact of the head car laminated glass.

In addition, Foraboschi (Foraboschi P, 2007), Asik (Asik M.Z et al, 2015) studied the mechanical properties of laminated glass deeply in theory, established a beam model and plate model, it is suitable for laminated glass.

\subsection{Finite Element Model}

ABAQUS is a powerful engineering finite element Simulate software that solves problems ranging from relatively simple linear analysis of many complex nonlinear problems. Many information that difficult to obtain by experiments can be powerful simulation functionality by ABAQUS (MABROUKI $\mathrm{T}$ et al, 2006).

In the finite element model, set the impact crusher end of the drill steel material AISII045, positive impact glass, and instant speed of $30 \mathrm{~m} / \mathrm{s}$.

\subsubsection{Model}

According to the failed state of glass crusher impact glass process, in this paper the analysis model contains the following main components: drill and glass. Because impact crusher glass process is extremely complex, the simulation aims to verify whether such a program can crash the window glass, so it is necessary to simplify the model and establish the necessary as sumptions. Therefore, the established assumptions: 1, impact crusher is in the local area when impact glass, it is assumed that the window glass is flat, not curved body; 2, assuming the simulation process crusher drill is rigid body; 3 , assuming that car window is single-layer glass, and assuming that the mechanical properties of glass has nothing to do with the time and temperature; 4, assuming that material meets VonMises yield criterion.

Geometry during the impact is shown in Figure 2. The finite element model Established on the basis of the geometric model, when meshed the workpiece model, it's necessary to consider the accuracy of the results, but also consider the simulation computation time. According to the software used in this paper, select C3D8I as the unit type, glass model has the size of $30 * 30 * 5 \mathrm{~mm}$, it was meshed into 33600 unit, and the drill was meshed into 27500 unit. The freedom of movement of the workpiece at the bottom of the three planes constraints.

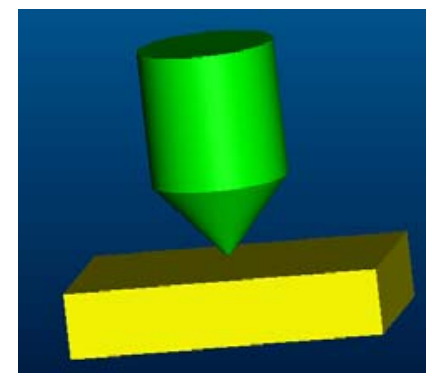

Fig 2. Model 


\subsubsection{Setting of contact}

Two contact models is establish: surface-surface contact between drill and the workpiece, common contact in entire model.

The settings include tangential contact with nature, the nature of the law, thermal conductivity and other parameters set, in which the most important is the nature of the tangential friction setting.

Because of the friction between the drill and the workpiece is complex, so using penalty function to handle the sliding Coulomb friction, increase the coefficient of sliding friction, thus simulating the friction between the glass and the status drill.

\subsection{Numerical analysis results}

Due to the hardness and brittleness of the glass surface, the stress within the conductive glass is very complex, in the event of failure damage, the material will instantly release accumulated stress failures along parts of cracks. Therefore, the propagation velocity of the stress and failure time undermine arise should be considered when study traces of glass production.

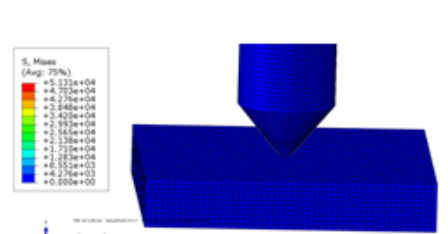

a) $4 \mu \mathrm{s}$

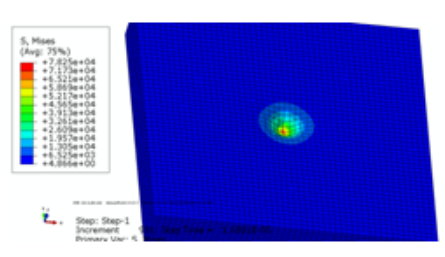

c) $16 \mu \mathrm{s}$

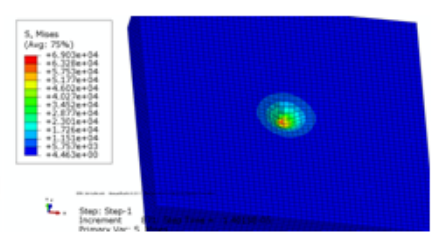

b) $14 \mu \mathrm{s}$

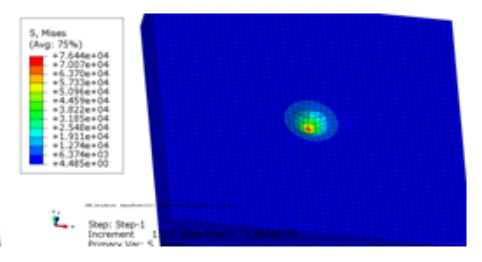

d) $18 \mu \mathrm{s}$
Fig 3. Dynamic stress distribution in glass

As shown in Figure 3,1 ) At the time of $4 \mu \mathrm{s}$, the drill came into contact with the glass, under the impact of drill, glass stress began to change; 2) At the time of $14 \mu \mathrm{s}$, the stress profile showed high stress concentration zone in the pre-impact drill point position, where the glass subjected to stress accumulation and concentration distribution in the incident surface of semicircular arc; 3) At the time of $16 \mu \mathrm{s}$, stress the value of this area is no longer substantially increased in the region are no longer expand, the impact stress concentration area with direction forward, and spread in the region near the point of impact; 4) At the time of $18 \mu \mathrm{s}$, stress begun to reduce, stop to diffusion region, the impact will be broken the glass.

Although the simulation is based on numerous assumptions and simplified model, but by experiment and simulation, we can get the following conclusions:

1 , if there is sufficient and appropriate impact force and suitable impact angle, the glass can be cracked by drill;

2 , through the simulation it can be confirmed that the critical factors of cracking the glass is shape of impact strength and the shape and hit angle of impact drill;

3. The focus of the next study is research the methods to quickly tearing the sandwich of glass bonded together, then occupants can escape easily.

\section{CONCLUSION}

In this paper a car glass broken machinery is presented, the stress distribution of the glass at different times is simulated based on software ABAQUS, it confirmed that the machinery can implement car window glass broken. By the crusher, in case of power failure, the purely mechanical can be used to crack the glass, so occupants can escape out of the car easily, it can greatly increase the safety of the occupants.

\section{REFERENCES}

A llen T J, Locke J Scranage J K. Size and distribution of fragments from vehicle windscreens forensic Science international, 1998, pp, 209-218

Asik M.Z, Tezcan S. A mathematical model for the behavior of laminated glass beams[J]. Computers \& Structures, 2015, 83(21-22): 1742-1753

Foraboschi P. Behavior and failure strength of laminated glass beams[J]. Journal of Engineering Mechanics, 2007, 133(12): 1290-1301

MABROUKI T, RIGAL J F. A contribution to a qualitative understanding of thermo-mechanical effects during chip formation in hard turning[J]. Journal of Materials Processing Technology, 2006, 176(1/3):214-221.

Nathan D.K, Behr R.A., Minor J.E., et al. Impact resistance of laminated glass using "sacrificial ply" design concept[J]. Journal of Architectural Engineering, 2010, 6(1): 24-34

Oda J, Zang M Y. Analysis of inpact fracture behavior of laminated glass of bi-layer type using discrete element method Key Engineering Materials, 1998, 145-149.

Oda J, Zang M Y. Simulation of dynamic fracture behavior of laminated glass by DEM. Trans 8th Calculation Dynamics Symp, JSME, 1995, 429-430

Seshadri M, Bennison S J, Jagota A, Mechanical response of cracked laminated plates a ctaMaterialia, 2002,50(18):44774490.

Yong T. Exploration of vehicle front windshield glass performance test methods. [J] Shanghai Auto, 2010, 53-56.

Zhao S, Dharani L.R, C hai L, et al. Dynamic response of laminated automotive glazing impacted by spherical featureless headform[J]. International Journal of Crashworthiness, 2012, 11(2): 105-114 